\title{
Correction to: The Effect of Natural or Simulated Altitude Training on High-Intensity Intermittent Running Performance in Team-Sport Athletes: A Meta-Analysis
}

\author{
Michael J. Hamlin ${ }^{1}$ (1) C Catherine A. Lizamore ${ }^{1} \cdot$ Will G. Hopkins ${ }^{2}$
}

Published online: 30 November 2017

(C) Springer International Publishing AG, part of Springer Nature 2017

Correction to: Sports Med

https://doi.org/10.1007/s40279-017-0809-9

Page 10, Fig. 2: The filled circle labelled "3" was plotted inaccurately and should have been in the "harmful" section of the graph, as shown in the corrected version below (Fig. 2):

Page 10, Fig. 3: The filled circle labelled " 3 " was plotted inaccurately and should have been in the "harmful" section of the graph. In addition, the open triangle labelled " $5 \mathrm{c}$ " was inaccurately plotted and should have been between the data points labelled "2" (filled circle) and "6" (filled triangle). These corrections are shown in the corrected version below (Fig. 3):

The original article can be found online at https://doi.org/10.1007/ s40279-017-0809-9.

Michael J. Hamlin

mike.hamlin@lincoln.ac.nz

1 Department of Tourism, Sport and Society, Lincoln University, PO Box 85084, Christchurch 7647, New Zealand

2 Institute of Sport, Exercise, and Active Living, Victoria University, Melbourne, VIC, Australia 


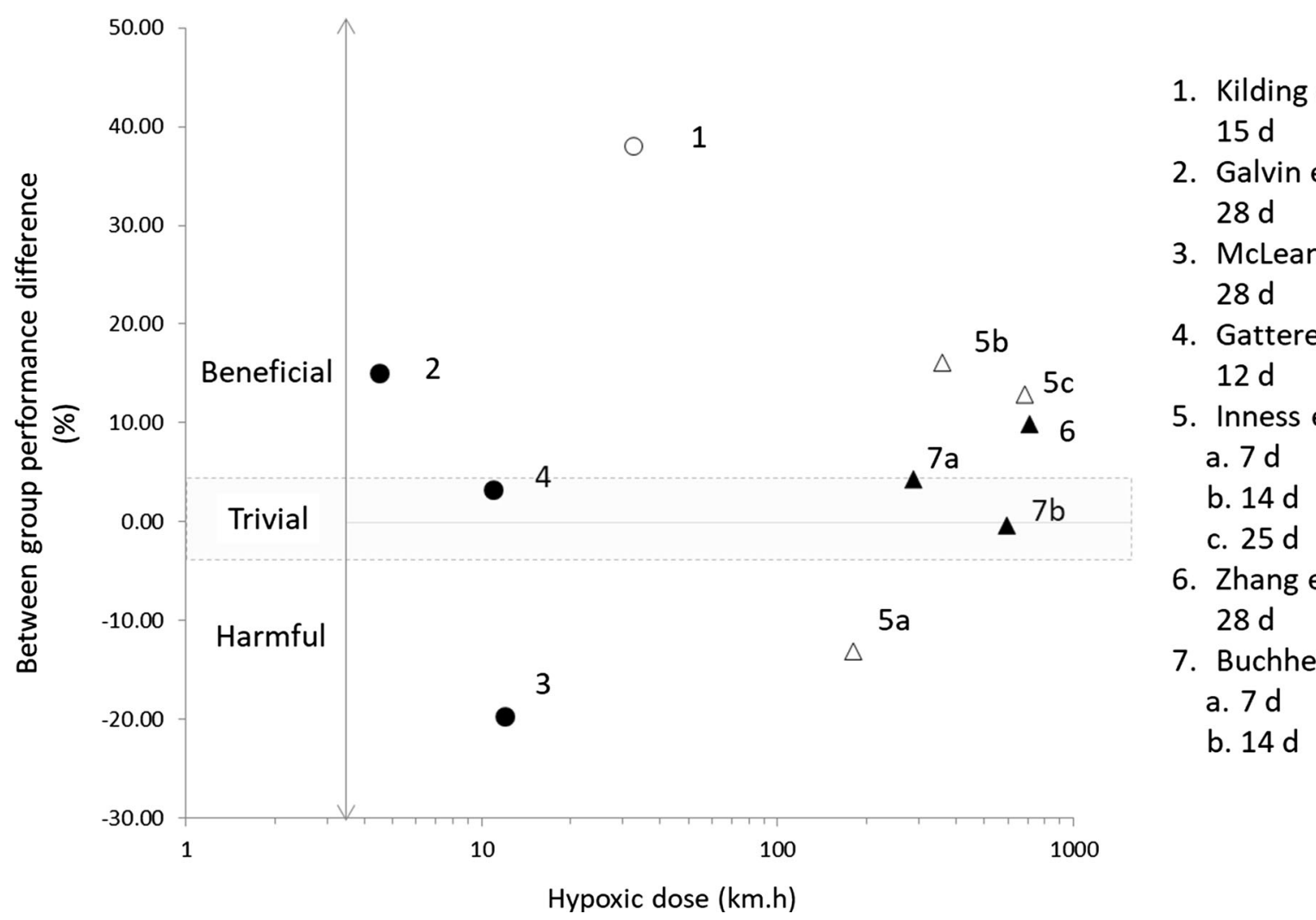

Fig. 2 The effect of hypoxic dose $(\mathrm{km} \mathrm{h})$ on change in highintensity, intermittent running performance (YYIR). Three studies have been excluded from this graph due to absence of a normoxic control group [36], risk of publication bias [40] and a particularly small sample size [39]. YYIR Yo-Yo intermittent recovery test, filled circle: hypoxic training, open circle: intermittent hypoxic exposure, filled triangle: live high, train low and high, open triangle: live high, train low, $d$ intervention duration (days), $k m ~ h$ kilometre hours (height above sea level in meters/1000 total number of hours of exposure) 


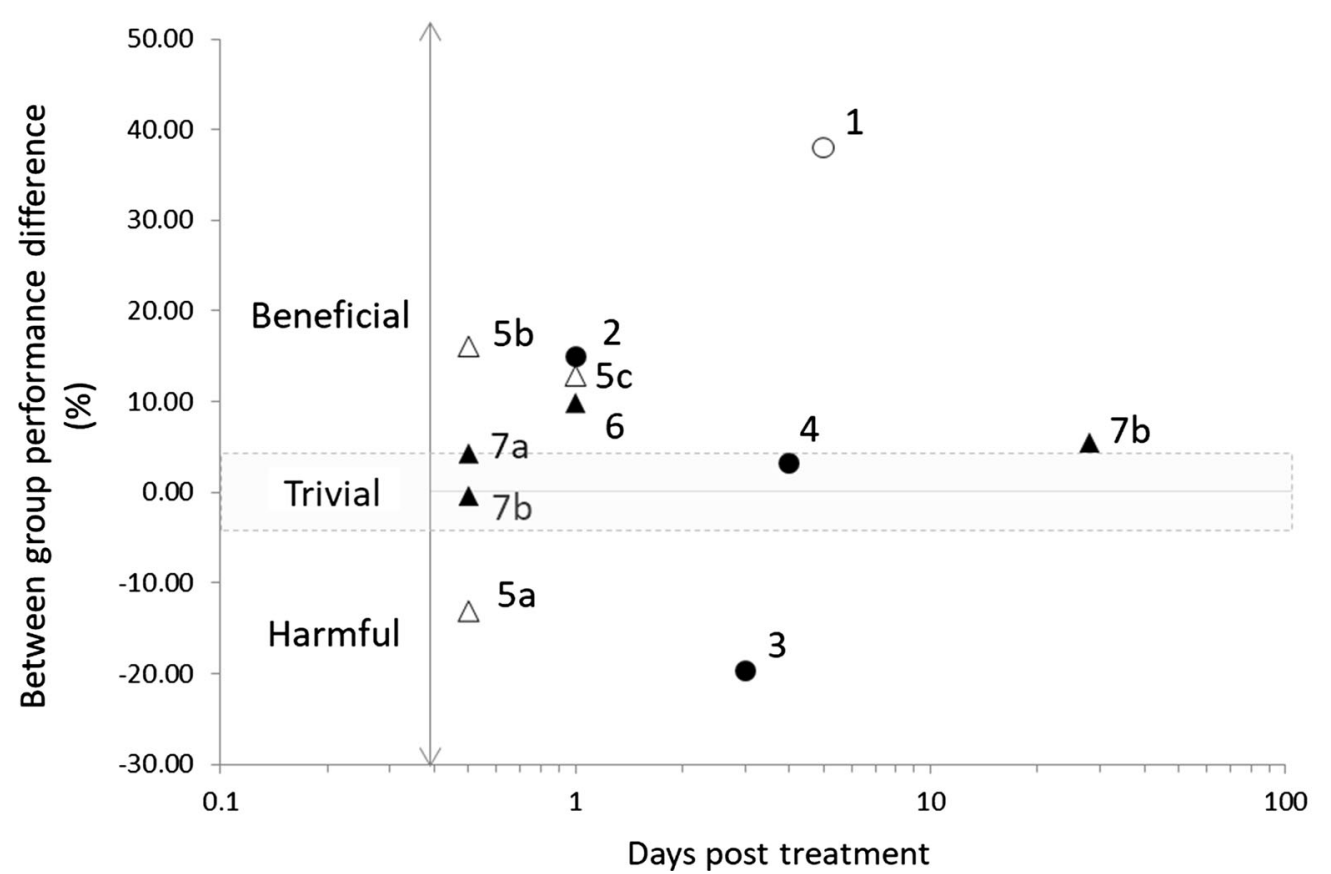

1. Kilding et al. [17] $33 \mathrm{~km} . \mathrm{h}, 15 \mathrm{~d}$

2. Galvin et al. [38] $5 \mathrm{~km} . \mathrm{h}, 28 \mathrm{~d}$

3. McLean et al. [41] $12 \mathrm{~km} . \mathrm{h}, 28 \mathrm{~d}$

4. Gatterer et al. [64] $11 \mathrm{~km} . \mathrm{h} ; 12 \mathrm{~d}$

5. Inness et al. [43]
a. $180 \mathrm{~km} . \mathrm{h}, 7 \mathrm{~d}$
b. $360 \mathrm{~km} . \mathrm{h}, 14 \mathrm{~d}$
c. $684 \mathrm{~km} . \mathrm{h}, 25 \mathrm{~d}$

6. Zhang et al. [42] $710 \mathrm{~km} . \mathrm{h}, 28 \mathrm{~d}$

7. Buchheit et al. [52]

a. $287 \mathrm{~km} . \mathrm{h}, 7 \mathrm{~d}$

b. $595 \mathrm{~km}$.h, $14 \mathrm{~d}$

Fig. 3 The post-intervention longevity of the change in highintensity, intermittent running performance (YYIR) following hypoxic exposure. Three studies have been excluded from this graph due to absence of a normoxic control group [36], risk of publication bias [40], and a particularly small sample size [39]. YYIR Yo-Yo intermittent recovery test, filled circle: hypoxic training, open circle: intermittent hypoxic exposure, filled triangle: live high, train low and high, open triangle: live high, train low, $d$ intervention duration (days), $\mathrm{km} \mathrm{h}$ kilometre hours (height above sea level in meters/1000 total number of hours of exposure) 